\title{
Research on Advertisement Marketing Model Based on Intelligent Terminals
}

\author{
Jiang Bing ${ }^{1, a}$ \\ ${ }^{1}$ Chongqing College of Electronic Engineering, ChongQing, 401331 \\ aemail: jiangbing401331@sina.com
}

Keywords: Advertisement Marketing, Intelligent Terminals, Strategy

\begin{abstract}
With the advancement of mobile media and technology, as mobile phones have become a multi-functional portable media intelligent handheld information terminal via a simple mobile phone, and gradually in all aspects of people's lives learning, entertainment show both traditional media and even the Internet do not have the advantage. This paper will be based on intelligent terminal advertising the current development status, communication and marketing from the perspective of analysis of its Advertisement marketing functions, applications focusing on smart advertising free advertising marketing effectiveness and potential analysis, market on this basis strategy. Integrated mobile terminal is an important platform for media convergence. Integration of a variety of media forms, carrying newspapers, radio, television, Internet and other mass media function, media networks play a fourth-specific interaction. The impact of advertising on the consumer intelligent terminals and advertising market environment brought about by the current assessed and noted the pitfalls and solutions.
\end{abstract}

\section{Theoretical Introduction of Intelligent Terminal Advertising}

Intelligent terminal advertising is defined as: intelligent terminal platform for the media, the use of the mobile Internet, text, video, pictures and other forms of communication links, product information dissemination through the intelligent terminal to the user, thus affecting consumer awareness so as to promote the purchase behavior. In mobile communications network for the distribution channels and online media all have propagation characteristics intelligent smart terminal advertising is actually an interactive online advertising, but more convenient than the Internet, fast, can accept advertising information anytime, anywhere.

Intelligent terminal advertising to achieve a precise orientation is the basis for the rise of intelligent terminal advertising market, and trust recommendation and multi-directional interaction of the chain to achieve shared social communication and advertising information to further enlarge advertising revenue between people. The core feature is relying on the mobile terminal platform, so its advertising with media mobility, convenience, immediacy, interactivity and other features. These features are unmatched by Internet advertising, traditional media is far behind ${ }^{[1]}$.

Intelligent terminal that is mobile intelligent terminal, refers to the mobile terminal has an open operating system platform, high-speed access capability and rich interactive interface, including smart intelligent terminal and tablets. Essentially, the use of advertising information changing consumer buying behavior or maintain a purpose to stimulate consumer buying patterns of strong economic activity will be referred to marketing activities, these requirements will determine the mode of transmission of advertising, distribution channels and information content and other advertising practices, so different advertising reach advertising effect is different. As a new advertising media, and establish a clear marketing goal is to implement the intelligent terminal advertising system must ensure that when precision marketing, advertising intelligent terminals also need to ensure accuracy and validity of marketing.

\section{Principles of Advertising Marketing of Intelligent Terminals}

A clear understanding of the principles and objectives of marketing is any marketing activities prior to the implementation of the requirements, the use of intelligent terminals ads embodiment of 
precision marketing also should recognize the hand of smart Advertisement marketing principles and objectives. Use determines the intelligent terminal advertising methods and implementation strategies are intelligent terminal advertising marketing principles and objectives. Implementation of the principle has guided precision marketing smart intelligent terminal advertising is the marketing body to implement the code of conduct Advertisement marketing activities, which specific marketing activities in the implementation of the following principles should be followed ${ }^{[2]}$. Fig. 1 shows the principles of advertising and marketing.

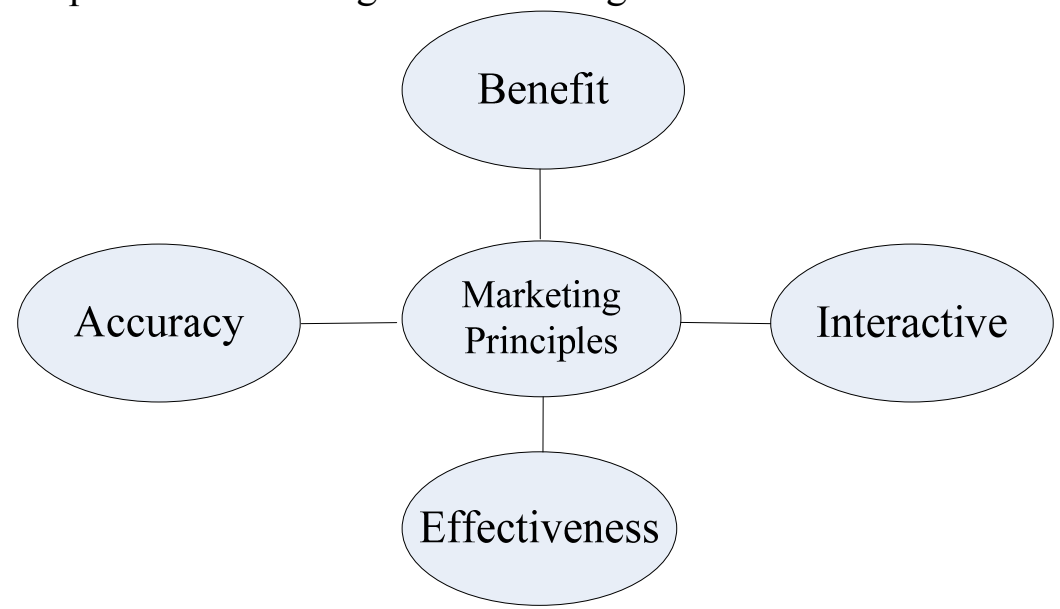

Fig. 1.The principles of advertising and marketing

Intelligent terminal to play a new advertising effectiveness and superiority of the most important new ability is accurate. Consumer demand determines the fine, precise push mode and the precise form of advertising, target customers precise positioning and advertising organizations are propagating their accuracy characteristics of play reflected. Companies choose to run advertising platform, forms of advertising and advertising content selection is to effectively achieve the desired goal, so companies in the implementation of intelligent terminal advertising precision marketing is to achieve the ultimate goal as the starting point is the principle of effectiveness. Bring waste too cumbersome and ineffective investment of smart intelligent terminal advertising practices, as well as customers hate and discontent, this kind of advertising is the need to strive to avoid.

Modern marketing concept is known as the most advanced marketing model is interactive two-way communication with consumers the way, one of the intelligent smart terminal advertising precision marketing basic ideas is interactive, intelligent smart terminal to provide a powerful interactive marketing support platform. In order to foster consumer loyalty and brand trust, we need to communicate directly with each other into the same consumer, the only way to understand the depth of the two sides to each other, thus interaction is very important. How to make the company's marketing activities to achieve through smart intelligent terminal advertising the lowest cost, economically rational profit-maximizing behavior. Therefore, the goal of smart intelligent terminal advertising implementation of precision marketing activity is in business to make money to enhance efficiency and to avoid the marketing itself to the enterprise serious negative impact ${ }^{[3]}$.

\section{The Advertising and Marketing Strategies}

No matter how advanced the technology, how the times, as long as the market exists so consumers will be always the core, user-oriented service-oriented marketing strategy, whether past or present and in the future is an important marketing strategy. Currently, domestic enterprises have widely accepted the concept of brand marketing, a good marketing strategy to make commodity activities into a virtuous cycle ${ }^{[4]}$.

People's consumption demand is multi-level demand, very large, and people need most is what products or services the consumer may itself is not very clear. Advertising clubs often can guide people's consumption habits, sometimes even become a sign of the times. Sometimes clear and let your audience understand their real needs, may be a very modest little advertising can impress consumers. Some new elements and changing the economic impact of the demand for traditional 
clothing, housing, consumer, messenger toward those needs refinement and diversified development, and rapid spread under the influence of advertising and marketing. From this perspective, it should be based on real, innovative, unique advertising and marketing to describe the quality of the goods, in order to stimulate consumer spending.

Psychology from the advertising point of view, the main source of human consumer behavior is hidden and revealed two ways to show it. Consumers in the choice of a commodity often more valued brand value of the enterprise. Competition in the market is the continued success of business subjects who can win the full trust of the business. From this perspective, the enterprise in order to improve their visibility, in describing the quality of goods necessary to ensure that new, real and unique. In short, the best choice for the promotion of consumer buying behavior is attention to their own brand of corporate culture promotion, thereby enhancing its credibility and good image in the minds of consumers.

With the development of private human trait intelligent terminals will become increasingly apparent, which requires intelligent terminals ads John enough in access methods, product performance car capable of petitions respect, caring, humane. Only "good faith" and "personalized" demand impress consumers, enterprises can further establish communication and contact with consumers. When the user of the intelligent terminal advertising content and information generated interest and trust, they will be easier to buy, consumer action can't be far.

\section{The Advertising and Marketing Evaluation}

The so-called intelligent terminal advertising refers to marketing effectiveness is based on intelligent terminal media campaign planning, creative advertising, plus production, as well as publication and implementation of the role and effectiveness of advertising and consumer-generated stakeholders. Intelligent terminal advertising, its evaluation methods and rating agencies associated with traditional advertising operates differently ${ }^{[5]}$.

A complete marketing campaign consists of two parts, namely the economic effects of the psychological effects of consumer and advertising itself, the use of intelligent terminals ads you can rely on a good balance between technological advantages to both aspects of marketing. We can see from the following four aspects to the main test advertising on the smart terminal effect: marketing efficiency, marketing performance, consumer stickiness and consumer marketing experience. The first is the marketing efficiency, this mainly reflected in lower service costs per unit of product marketing costs, increase marketing precision, increased sensitivity to market corporate marketing and expand sales change diffusivity and awareness of marketing information. Fig.2 shows the advertising and marketing evaluation measures.

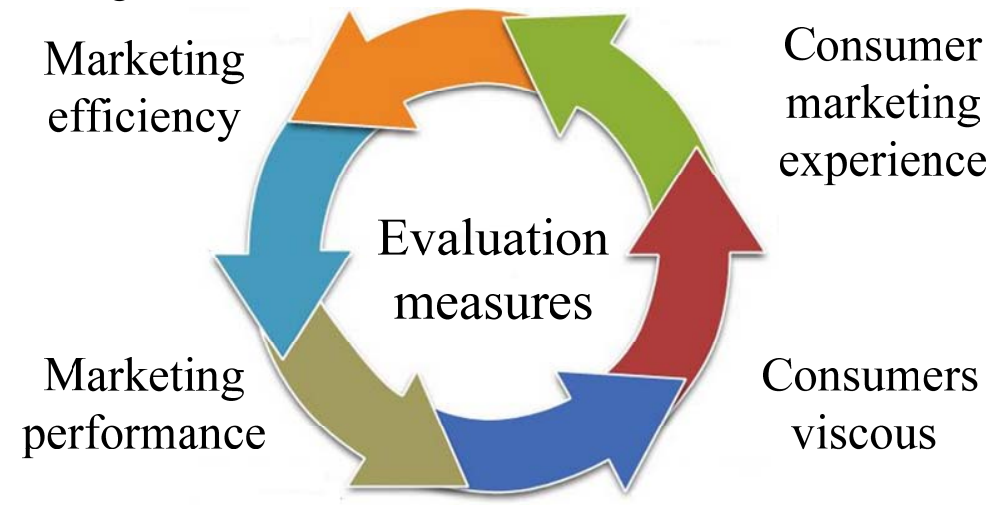

Fig. 2 .The advertising and marketing evaluation measures

Intelligent terminal advertisement marketing aspects of the performance evaluation must consider the brand to create value for advertisers in marketing, advertising intelligent terminal situation. To do intelligent terminal advertising precision marketing, we must focus on the customer response marketing, consumer stickiness and marketing experience, which is to do the smart terminal advertising can' be ignored important test indicators. Enterprises from consumer product 
satisfaction, consumer interaction will, consumers prefer the ability to identify the product and consumer confidence as well as aspects of the business to increase consumer marketing experience. Consumers should consider the viscous consumer spending frequency, consumer price sensitivity, consumer interactive index, emotional dependence and tolerance of consumers to emergencies. Consumer brand emotional dependence, repeat purchase, for emergencies tolerance, and disregard for the price index are all consumers can evaluate viscous. Users' emotions are abstract in nature, in order to quantify consumer stickiness related indicators actually not very convenient.

\section{Conclusions}

The rapid development and popularization of intelligent terminals, to develop a new advertisement marketing model, it also brings huge profits to producers. Based on the objectives and principles of intelligent terminal advertising on the basis of precision marketing, summed up the implementation of intelligent terminals ad precise marketing Strategy for the use of the intelligent terminal advertising precision marketing in practice indicate the specific steps and strategies for advertisers, companies Times do the smart terminal smart terminal advertising provides precision marketing ideas and methods. On the technical side should increase research and development and introduction efforts, improve existing information dissemination aromatic type and transmission speed, so that all aspects of the smart phone truly intelligent, become facilitate communication between businesses and consumers, advertisers and audiences communication platform for efficient and effective dissemination of information and facilitate people's lives play a greater role.

\section{References}

[1] Eric Undeen. Responding to the Demands of Mobile-Banking consumers[J]. US Banker, February, 2008(11):33-42.

[2] Ma Y, Hankins R., Racz D. iLoc: A Framework for Incremental Location State Acquisition and Prediction Based on Mobile Sensors. Proc. 18th ACM Conf. Information and Knowledge Management (CIKM), ACM Press, 2009: 51-62.

[3] Tudor G. Mobile Advertising in Vehicular Ad-hoc Networks [J]. BcS Thesis Politehnica University, Bucharest, 2010(6): 43-67.

[4] Chon Y., Talipov E., Cha H. Autonomous Management of Personalized Location Provider for Mobile Services, tech. report, Dept. of Computer Science, Yonsei Univ., 2010: 86-93.

[5] Yonsei Univ. LifeMap: A Smartphone Based Context Provider for Location Based Services [J]. Pervasive Computing, 2011(7): 24-33. 